\title{
Urinary excretion of electrolytes and their correlation with clinical parameters in chronic kidney disease
}

Ashfaq Ahmad Shah Bukhari, Mehwish Durrani, Zulfania Khan, Muhammad Shafiq, Saman Tauqir, Aziz Ur Rehman

\section{Submitted}

March 28, 2020

Accepted

April 20, 2020

\section{Author Information}

Dr. Ashaf Ahmad Shah Bukhari

Associate Professor, Department of Physiology, Rehman Medical College, Peshawar, Pakistan. (Corresponding Author) Email

ashfaq.bukhari@rmi.edu.pk

\section{Dr. Mehwish Durrani}

Associate Professor,

Department of Biochemistry, Rehman Medical College, Peshawar, Pakistan.

\section{Dr. Zulfania Khan}

Assistant Professor, Department of Physiology, Rehman Medical College, Peshawar, Pakistan

\section{Dr. Muhammad Shafiq} Professor, Department of Biochemistry, Rehman Medical College, Peshawar, Pakistan.

Dr. Saman Tauqir Lecturer, Department of Physiology, Rehman College of Dentistry, Peshawar.

\section{Dr. Aziz ur Rehman}

Assistant Professor, Department of Biochemistry, Rehman Medical College, Peshawar, Pakistan.

Citation: Bukhari AAS, Durrani M, Khan Z, Shafiq M, Tauqir S, Rehman A. Urinary excretion of electrolytes and their correlation with clinical parameters in chronic kidney disease. J Rehman Med Inst. 2020 Apr-Jun;6(2):8-11

\begin{abstract}
Introduction: With the increasing incidence of chronic renal disease on a global scale, it is important to document the chemical abnormalities that not only indicate deteriorating renal function, but also aggravate the clinical picture by causing sustained electrolyte imbalance, ultimately contributing to End Stage Renal Disease (ESRD).
\end{abstract}

Objective: To investigate 24-hr urinary electrolytes excretion of non-dialysis patients presenting with history of chronic kidney disease (CKD) and correlate the biochemical abnormalities with clinical parameters.

Materials \& Methods: A total of 100 patients with CKD were included in a private clinic setup from February 2017 to December 2019 to retrospectively analyze the relationship of 24-hr urinary electrolytes with clinical indicators in these subjects. Besides demographic data, biochemical indices of concern were obtained through standard laboratory techniques. The patients were then divided on the basis of results into four quartile groups. Descriptive data analysis was done through SPSS 22.0.

Results: Nephropathic patients had low eGFR, albumin, hemoglobin, blood calcium as well as 24-hr urine calcium and had high body mass index (BMI), systolic blood pressure, diastolic blood pressure, blood creatinine, blood sodium and 24-hr urine sodium According to quartiles of 24-hr urinary sodium; in the Q4 group, 24-hr urine protein, 24-hr urine potassium and 24-hr urine calcium were the highest while according to quartile of 24-hr urinary potassium; the Q3 group had the highest 24-hr urine protein. According to quartile of urinary calcium, Q4 group blood calcium, 24-hr urine sodium and 24-hr urine potassium was high. The results revealed a positive correlation of 24-hr urinary sodium and potassium with 24 -hr urine protein and a negative correlation of 24-hr urinary calcium with 24-hr urine protein.

Conclusion: The levels of urinary electrolytes in patients with CKD are associated with urinary protein. It is, therefore, recommended that the above-mentioned disease be treated in these patients for their proper management.

Keywords: Urine Chemistry; Proteinuria; Rena Insufficiency, Chronic.

The authors declared no conflict of interest. All authors contributed substantially to the planning of research, data collection, data analysis, and write-up of the article, and agreed to be accountable for all aspects of the work.

\section{INTRODUCTION}

With the development of social economy, incidence of chronic kidney disease (CKD) is increasing every year and most of the patients eventually enter the end-stage of renal disease (ESRD), although the time from onset to ESRD is controllable. Blood pressure, blood sugar, urine protein and urinary electrolytes are closely related to kidney function. ${ }^{1,2}$ Kidney is an important organ for maintaining electrolyte balance in the body, its organic disease is bound to cause electrolyte imbalance; as a consequence, the occurrence of electrolyte imbalance is high in patients suffering from CKD, leading to altered urinary excretion of sodium, potassium, calcium and phosphorus. Hyperkalemia is a common electrolyte disorder in CKD patients and studies have shown that hypokalemia is related to the progression of chronic kidney disease. ${ }^{4}$ In type 2 diabetic patients with normal renal function, high urine potassium is associated with slow decline in renal function and reduced onset of symptoms of cardiovascular complications. ${ }^{5}$ The kidneys of CKD patients are compromised to regulate water and electrolyte levels and the impaired balance function makes the patient prone to hypernatremia and increased urinary sodium excretion promoting increase in urine protein. ${ }^{6,7}$ There are very few studies elucidating the relationship between urinary electrolytes, urinary protein and other clinical indicators. Therefore, this study was designed to assess urinary excretion of electrolytes in different stages of CKD and to ascertain their correlation with clinical features in these patients.

\section{MATERIALS \& METHODS}

\section{Subjects}

One hundred patients were enrolled from February 2017 to Dec 2019 in a private clinic setup. Venous blood and 24-hr urine were collected from each subject for determination of electrolytes and other variables.

Inclusion criteria were: 1) In line with the 2012 International Kidney Disease Organization "kidney disease: improving global prognosis". Kidney disease: Improving global outcomes 
guidelines (KDIGO). CKD was defined as per guidelines. ${ }^{8}$ 2) Estimated glomerular filtration rate $(\mathrm{eGFR})>15 \mathrm{~mL}$ (in.1.73 $\mathrm{m} 2)$.

Exclusion criteria were subjects having acute kidney injury, decompensated cirrhosis, acute heart failure, blood infection as well as patients undergoing hemodialysis, peritoneal dialysis and kidney transplantation. Subjects using immunosuppressant drugs and glucocorticoids and those having malignant tumor were also excluded.

Informed consent was obtained from all patients.

\section{Methods}

Baseline demographic data were collected, including age, body mass index (BMI), systolic blood pressure, complications and current use of drugs. Venous blood was collected from each patient and analyzed for sodium, potassium, calcium, hemoglobin, total cholesterol, triglycerides, albumin and creatinine. Twenty-four urine sodium, 24-hr urine potassium, 24-hr urine calcium and 24-hr urine protein were assayed in 24hr urine of every subject. The eGFR was estimated by CKDEPI (2009). ${ }^{9}$

\section{Statistical analysis}

SPSS 20.0 statistical software was used for data analysis. The continuous variables with normal distribution were expressed as means \pm standard deviation; continuous variables that did not conform to the normal distribution were described as median (quartile) $[\mathrm{M}(\mathrm{Q} 1, \mathrm{Q} 3)]$ and categorical variables were described in the form of percentages. The data of normal distribution were compared by T-test or one-way ANOVA; SNK method was used when the variance was homogeneous. For comparison, Kruskall-Wallis test was used to test the variance. Nonparametric method was used to compare non normal distribution data between groups. Chi Square test was used to compare the categorical variables; $p$ value $\leq 0.05$ denoted statistical significance.

\section{RESULTS}

Comparison of CKD patients with different degrees of proteinuria with clinical indicators

The patients were divided into nephropathy-range proteinuria group (24-hr urine protein $\geq 3.5 \mathrm{~g}$ ) and non-nephropathy range proteinuria group (24-hr urine protein $<3.5 \mathrm{~g}$ ). There were no significant differences in age, serum potassium, and 24-hr urine potassium between the two groups. Non-nephropathy range proteinuria group compared with nephropathy range proteinuria group; BMI, systolic blood pressure, diastolic blood pressure, blood creatinine, blood sodium, 24-hr urine sodium increased, while eGFR, albumin, hemoglobin, blood calcium, 24-hr urine calcium decreased respectively. The difference was statistically significant between groups (Table 1and 2).

Table 1: Clinical characteristics and laboratory findings of patients with CKD according to the degree of proteinuria

\begin{tabular}{|l|c|c|c|}
\hline \multicolumn{1}{|c|}{ Clinical indicators } & $\begin{array}{c}\mathbf{2 4} \text { hour Urine } \\
\text { Protein } \\
\mathbf{2 3 . 5} \mathbf{g / d}(\boldsymbol{n}=\mathbf{7 6})\end{array}$ & $\begin{array}{c}\mathbf{2 4} \text { hour Urine } \\
\text { Protein } \\
\mathbf{3 . 5} \mathbf{g} / \mathbf{d} \mathbf{( n = 2 4 )}\end{array}$ & p value \\
\hline Age (years) & $46.65 \pm 14.01$ & $48.70 \pm 15.25$ & 0.138 \\
\hline BMI $(\mathrm{kg} / \mathrm{m} 2)$ & $23.47 \pm 2.60$ & $24.32 \pm 2.80$ & 0.005 \\
\hline Systolic blood pressure $(\mathrm{mmHg})$ & $131.45 \pm 18.05$ & $139.29 \pm 21.47$ & $<0.001$ \\
\hline Diastolic blood pressure $(\mathrm{mmHg})$ & $79.83 \pm 11.20$ & $83.20 \pm 12.40$ & 0.003 \\
\hline eGFR $[\mathrm{mL} / \mathrm{min} \cdot 1.73 \mathrm{~m} 2)]$ & $77.20 \pm 31.40$ & $69.43 \pm 30.81$ & 0.009 \\
\hline Creatinine $(\mu \mathrm{mol} / \mathrm{L})$ & $102.63 \pm 58.70$ & $120.40 \pm 69.50$ & 0.003 \\
\hline Albumin $(\mathrm{g} / \mathrm{L})$ & $36.30 \pm 4.75$ & $22.30 \pm 6.42$ & $<0.001$ \\
\hline Triglycerides $(\mathrm{mmol} / \mathrm{L})$ & $1.40 \pm 1.29$ & $2.39 \pm 1.50$ & $<0.001$ \\
\hline Total cholesterol $(\mathrm{mmol} / \mathrm{L})$ & $4.50 \pm 1.19$ & $8.29 \pm 2.30$ & $<0.001$ \\
\hline Hemoglobin $(\mathrm{g} / \mathrm{L})$ & $126.50 \pm 20.85$ & $120.60 \pm 23.51$ & 0.005 \\
\hline
\end{tabular}

Table 2: Electrolyte findings of patients with CKD according to the degree of proteinuria

\begin{tabular}{|l|c|c|c|}
\hline \multicolumn{1}{|c|}{ Clinical indicators } & $\begin{array}{c}\mathbf{2 4} \text { hour Urine } \\
\text { Protein } \\
\mathbf{3 . 5} \mathbf{g} / \mathbf{d}(\boldsymbol{n}=\mathbf{7 6})\end{array}$ & $\begin{array}{c}\mathbf{2 4} \text { hour Urine } \\
\text { Protein } \\
\mathbf{2 3 . 5} \mathbf{g} / \mathbf{d}(\boldsymbol{n}=\mathbf{2 4})\end{array}$ & p value \\
\hline Blood potassium $(\mu \mathrm{mol} / \mathrm{L}$ & $03.50 \pm 0.35$ & $03.50 \pm 0.39$ & 0.926 \\
\hline Blood calcium $(\mu \mathrm{mol} / \mathrm{L}$ & $02.21 \pm 0.13$ & $01.99 \pm 0.18$ & $<0.001$ \\
\hline Blood sodium $(\mu \mathrm{mol} / \mathrm{L})$ & $138.59 \pm 2.500$ & $141.38 \pm 3.300$ & 0.002 \\
\hline 24-hr Urine sodium $(\mathrm{mmol} / \mathrm{d})$ & $135.19 \pm 67.20$ & $160.40 \pm 77.70$ & $<0.001$ \\
\hline 24-hr Urine potassium $(\mathrm{mmol} / \mathrm{d})$ & $32.70 \pm 14.33$ & $34.70 \pm 10.20$ & 0.099 \\
\hline 24-hr Urine calcium $(\mathrm{mmol} / \mathrm{d})$ & $03.10 \pm 1.10$ & $1.70 \pm 1.39$ & $<0.001$ \\
\hline
\end{tabular}

Comparison of various clinical indicators of 24-hour urine electrolyte quartiles

According to the 24-hr urine sodium level, the patients were divided into four quartile groups: Q1 $(\leq 87.20 \mathrm{mmol} / \mathrm{d})$, Q2 (87.20 -124.11 $\mathrm{mmol} / \mathrm{d})$, Q3 (124.11-176.25 $\mathrm{mmol} / \mathrm{d}), \quad$ Q4
(>176.25 mmol/d). The Q4 group had the highest levels of 24-hr urine protein, 24-hr urine potassium and 24-hr urine calcium, while the levels of these indicators were lowest in Q1 group (Table 3). 
Table 3: Patients with CKD according to quartiles of 24-hour urinary sodium

\begin{tabular}{|c|c|c|c|c|c|}
\hline Clinical indicators & $\begin{array}{c}\mathrm{Q} 1 \\
\leq 87.20 \\
\mathrm{mmol} / \mathrm{d} \\
(n=25)\end{array}$ & $\begin{array}{c}\mathrm{Q} 2 \\
87.20-124.11 \\
\mathrm{mmol} / \mathrm{d} \\
(n=25)\end{array}$ & $\begin{array}{c}\mathrm{Q} 3 \\
124.11-176.25 \\
\mathrm{mmol} / \mathrm{d} \\
(n=25)\end{array}$ & $\begin{array}{c}\mathrm{Q} 4 \\
>176.25 \\
\mathrm{mmol} / \mathrm{d} \\
(n=25)\end{array}$ & p value \\
\hline Age (years) & $52.18 \pm 15.50$ & $49.56 \pm 14.30$ & $52.15 \pm 13.50$ & $51.20 \pm 14.10$ & 0.370 \\
\hline 24-hr Urine Protein $(\mathrm{g} / \mathrm{d})$ & $0.84(0.39,2.90)$ & $0.86(0.20,2.1)$ & $0.99(0.28,2.5)$ & $2.30(0.40,4.9)$ & $<0.001$ \\
\hline eGFR $[\mathrm{mL} /(\min \cdot 1.73 \mathrm{~m} 2)]$ & $71.70 \pm 32.41$ & $78.66 \pm 32.30$ & $77.10 \pm 35.29$ & $77.56 \pm 31.50$ & 0.203 \\
\hline Blood sodium $(\mu \mathrm{mol} / \mathrm{L})$ & $140.50 \pm 3.10$ & $140.72 \pm 2.50$ & $141.00 \pm 2.10$ & $141.01 \pm 2.40$ & 0.231 \\
\hline Serum potassium $(\mu \mathrm{mol} / \mathrm{L})$ & $3.30 \pm 0.41$ & $3.57 \pm 0.41$ & $3.89 \pm 0.40$ & $3.80 \pm 0.40$ & 0.874 \\
\hline Blood calcium $(\mu \mathrm{mol} / \mathrm{L})$ & $2.01 \pm 0.15$ & $2.10 \pm 0.15$ & $2.12 \pm 0.14$ & $2.09 \pm 0.11$ & 0.061 \\
\hline 24-hr Urine sodium $(\mathrm{mmol} / \mathrm{d})$ & $58.10 \pm 18.40$ & $105.20 \pm 09.88$ & $145.51 \pm 13.70$ & $229.36 \pm 55.40$ & $<0.001$ \\
\hline 24-hr Urine potassium $(\mathrm{mmol} / \mathrm{d})$ & $26.30 \pm 11.42$ & $31.66 \pm 10.40$ & $34.10 \pm 12.70$ & $41.70 \pm 12.55$ & $<0.001$ \\
\hline 24-hr Urine calcium $(\mathrm{mmol} / \mathrm{d})$ & $1.80 \pm 1.70$ & $2.61 \pm 1.77$ & $2.83 \pm 2.00$ & $3.90 \pm 2.40$ & $<0.001$ \\
\hline
\end{tabular}

When the patients were divided into four quartile groups on the basis of 24-hr urine potassium level; Q1 ( $\leq 22.65 \mathrm{mmol} / \mathrm{d})$, Q2 (22.65-30.30 mmol/d), Q3 (30.30-39.10 mmol/d), Q4 (>39.10 $\mathrm{mmol} / \mathrm{d}$ ), levels of 24-hr urine sodium, 24-hr urine calcium and 24-hr urine potassium were highest in the Q4 group and lowest in the Q1 group. The differences between the groups were statistically significant. The Q3 group had the highest 24-hr urine protein and the Q1 group had the lowest; the difference was statistically significant, while all the groups did not differ significantly in serum creatinine and eGFR (Table 4).

Table 4: Patients with CKD according to quartiles of 24-hour urinary potassium

\begin{tabular}{|c|c|c|c|c|c|}
\hline Clinical indicators & $\begin{array}{c}\mathrm{Q} 1 \\
\leq 22.65 \\
\mathrm{mmol} / \mathrm{d} \\
(n=25)\end{array}$ & $\begin{array}{c}\mathrm{Q} 2 \\
22.65-30.30 \\
\mathrm{mmol} / \mathrm{d} \\
(n=25)\end{array}$ & $\begin{array}{c}\mathrm{Q} 3 \\
30.30-39.10 \\
\mathrm{mmol} / \mathrm{d} \\
(n=26)\end{array}$ & $\begin{array}{c}\mathrm{Q} 4 \\
>39.10 \\
\mathrm{mmol} / \mathrm{d} \\
(n=24)\end{array}$ & p value \\
\hline Age (years) & $51.09 \pm 15.80$ & $51.30 \pm 14.30$ & $51.50 \pm 13.20$ & $51.20 \pm 14.10$ & 0.988 \\
\hline 24-hr Urine protein $(\mathrm{g} / \mathrm{d})$ & $0.81(0.29,2.4)$ & $1.10(0.48,2.50)$ & $1.40(0.40,4.4)$ & $1.38(0.55,3.30)$ & 0.004 \\
\hline eGFR $[\mathrm{mL} /(\min \cdot 1.73 \mathrm{~m} 2)]$ & $76.92 \pm 30.59$ & $70.60 \pm 31.50$ & $72.70 \pm 30.30$ & $73.35 \pm 28.41$ & 0.541 \\
\hline Creatinine $(\mu \mathrm{mol} / \mathrm{L})$ & $104.30 \pm 40.20$ & $113.40 \pm 69.60$ & $115.48 \pm 61.50$ & $109.40 \pm 41.50$ & 0.329 \\
\hline Blood sodium $(\mu \mathrm{mol} / \mathrm{L})$ & $139.15 \pm 2.40$ & $139.07 \pm 2.40$ & $138.80 \pm 2.40$ & $138.70 \pm 2.60$ & 0.820 \\
\hline Serum potassium $(\mu \mathrm{mol} / \mathrm{L})$ & $3.50 \pm 0.39$ & $3.60 \pm 0.35$ & $3.73 \pm 0.42$ & $3.77 \pm 0.43$ & $<0.001$ \\
\hline Blood calcium $(\mu \mathrm{mol} / \mathrm{L})$ & $2.26 \pm 0.15$ & $2.25 \pm 0.12$ & $2.126 \pm 0.14$ & $2.31 \pm 0.10$ & 0.043 \\
\hline 24-hr Urine sodium $(\mathrm{mmol} / \mathrm{d})$ & $90.10 \pm 39.71$ & $122.20 \pm 49.11$ & $147.29 \pm 65.09$ & $173.90 \pm 71.49$ & $<0.001$ \\
\hline 24-hr Urine potassium $(\mathrm{mmol} / \mathrm{d})$ & $16.71 \pm 3.49$ & $25.50 \pm 2.11$ & $33.50 \pm 2.30$ & $49.80 \pm 12.70$ & $<0.001$ \\
\hline 24-hr Urine calcium (mmol/d) & $2.39 \pm 1.50$ & $2.77 \pm 2.01$ & $2.97 \pm 2.09$ & $3.40 \pm 2.39$ & $<0.001$ \\
\hline
\end{tabular}

When the patients were divided into four quartile groups on the basis of 24-hr urine calcium level; Q1 $(\leq 1.065 \mathrm{mmol} / \mathrm{d})$, Q2 $(1.065-2.160 \mathrm{mmol} / \mathrm{d})$, Q3 $(2.160-3.755 \mathrm{mmol} / \mathrm{d})$ and Q4 (>3.755 $\mathrm{mmol} / \mathrm{d}$ ), the Q4 group had higher levels of blood calcium, 24-hr urine sodium and 24-hr urine potassium as compared to other quartile groups; the differences between the groups were statistically significant. Q4 group had very low levels of 24-hr urine protein, serum creatinine and potassium and had highest eGFR, while the Q1 group revealed opposite trend in these variables; the differences between groups were statistically significant (Table 5).

Table 5: Patients with CKD according to quartiles of 24-hour urinary calcium

\begin{tabular}{|c|c|c|c|c|c|}
\hline Clinical indicators & $\begin{array}{c}\mathrm{Q} 1 \\
\leq 1.065 \\
\mathrm{mmol} / \mathrm{d} \\
(n=25)\end{array}$ & $\begin{array}{c}\mathrm{Q} 2 \\
1.065-2.160 \\
\mathrm{mmol} / \mathrm{d} \\
(n=26)\end{array}$ & $\begin{array}{c}\mathrm{Q} 3 \\
2.160-3.755 \\
\mathrm{mmol} / \mathrm{d} \\
(n=24)\end{array}$ & $\begin{array}{c}\mathrm{Q} 4 \\
>3.755 \\
\mathrm{mmol} / \mathrm{d} \\
(n=25)\end{array}$ & p value \\
\hline Age (years) & $51.30 \pm 15.29$ & $47.40 \pm 14.70$ & $44.40 \pm 13.50$ & $45.77 \pm 13.10$ & $<0.001$ \\
\hline 24-hr Urine protein (g/ d) & $2.10(0.61,5.01)$ & $1.03(0.30,2.98)$ & $0.70(0.23,2.00)$ & $0.51 \quad(0.21,1.30)$ & $<0.001$ \\
\hline $\mathrm{eGFR}[\mathrm{mL} /(\mathrm{min} \cdot 1.73 \mathrm{~m} 2)]$ & $52.00 \pm 30.77$ & $70.92 \pm 31.40$ & $84.85 \pm 29.10$ & $94.29 \pm 20.60$ & $<0.001$ \\
\hline Creatinine $(\mu \mathrm{mol} / \mathrm{L})$ & $149.80 \pm 70.20$ & $111.80 \pm 60.80$ & $91.22 \pm 48.33$ & $76.29 \pm 29.30$ & $<0.001$ \\
\hline Blood sodium $(\mu \mathrm{mol} / \mathrm{L})$ & $141.00 \pm 2.90$ & $140.50 \pm 2.20$ & $140.40 \pm 2.89$ & $141.00 \pm 2.00$ & 0.814 \\
\hline Serum potassium $(\mu \mathrm{mol} / \mathrm{L})$ & $3.96 \pm 0.49$ & $3.80 \pm 0.38$ & $3.71 \pm 0.32$ & $3.60 \pm 0.30$ & $<0.001$ \\
\hline Blood calcium $(\mu \mathrm{mol} / \mathrm{L})$ & $2.31 \pm 0.28$ & $2.36 \pm 0.18$ & $2.38 \pm 0.121$ & $2.40 \pm 0.20$ & $<0.001$ \\
\hline 24-hr Urine sodium $(\mathrm{mmol} / \mathrm{d})$ & $106.76 \pm 50.70$ & $132.70 \pm 60.00$ & $149.90 \pm 70.70$ & $166.50 \pm 70.51$ & $<0.001$ \\
\hline 24-hr Urine potassium $(\mathrm{mmol} / \mathrm{d})$ & $31.44 \pm 14.58$ & $32.30 \pm 12.10$ & $33.10 \pm 10.50$ & $36.19 \pm 13.15$ & 0.010 \\
\hline 24-hr Urine calcium (mmol/d) & $0.50 \pm 0.25$ & $1.47 \pm 0.30$ & $2.81 \pm 0.39$ & $5.39 \pm 1.70$ & $<0.001$ \\
\hline
\end{tabular}




\section{DISCUSSION}

This study was carried out on non-dialysis patients having CKD. The results show that the urinary excretion of sodium and potassium is comparable in these patients; although eGFR was decreased and urinary calcium excretion also showed a downward trend. The CKD patients who were in the ESRD state had developed proteinuria as one of the characteristic manifestations, which also accelerates deterioration of kidney function. Related research found that renal dysfunction in elderly patients with CKD is one of the important reasons for the decline in the presence of high levels of proteinuria. ${ }^{10}$ The 24 hour urine electrolyte research on CKD patients has become a major hot spot. This study was aimed to analyze the relevance of clinical features to urine electrolytes; urine protein was the focus of analysis. Related research shows that increased urinary sodium and potassium excretion augments the extent of proteinuria and the progress of renal dysfunction. ${ }^{11}$ The present study showed increased urine sodium and potassium with increased urinary protein excretion and these findings are compatible with the results of Martinez et al. ${ }^{11}$

Some studies have found that urinary protein is increased with high uric-acidification and dysfunction in CKD patients ${ }^{12}$ and the proteinuria can be improved by salt restriction in these patients. ${ }^{13}$ The association of urine electrolytes with urine protein shown in this study suggests that increase in urinary sodium and potassium excretion may intensify the renal pathology causing structural damage, thereby increasing urine protein; on the contrary, the increased urinary calcium may prevent the progression of disease process in the pathological structure of the kidney.

It is reported that high blood phosphorus increases cardiovascular events and the risk of their occurrence. ${ }^{14}$ Further research is needed to explore the relationship between urinary electrolyte excretion and kidney disease progression as well as the risk of cardiovascular and other diseases in such patients to ascertain the association between urine electrolytes and prognosis in CKD.

In summary, the decline in renal function increases the severity of disease in CKD patients; urinary protein excretion increases with increased excretion of sodium and potassium as well as decreased excretion of urinary calcium which may further deteriorate kidney function. Therefore, suggesting that the management of urine electrolyte levels in patients with chronic kidney disease should receive more and more attention.

\section{REFERENCES}

1. Kim CS, Choi HS, Bae EH, Kim SW, Ma SK. Optimal blood pressure target and measurement in patients with chronic kidney disease. Korean J Intern Med. 2019;3461181-7.

2. Yamanouchi M, Furuichi K, Hoshin, Toyama T, Hara A, Shimizu $M$ et al. Nonproteinuric versus proteinuric phenotypes in diabetic kidney disease: a propensity score-matched analysis of a nationwide, biopsy-based cohort study. Diabetes Care. 2019;42(5):891-902.

3. Koh KH, Wei-Soon LH, Jun L, Lui-Sian LN, Hui-Hong CT. Study of low salt diet in hypertensive patients with chronic kidney disease. Med J Malaysia. 2018;73(6):376-381.

4. Kim HW, Park JT, Yoo TH, Lee J, Chung $\mathrm{W}$, Lee $\mathrm{KB}$ et al. Urinary potassium excretion and progression of CKD. Clin $\mathbf{J}$ Am Soc Nephrol. 2019;14(3):330-40.

5. Araki S, Haneda M, Koya D, Kondo K, Tanaka S, Arima $\mathrm{H}$ et al. Urinary potassium excretion and renal and cardiovascular complications in patients with type 2 diabetes and normal renal function. Clin J Am Soc Nephrol. 2015;10(12:2152-8

6. Eren MA, Koyuncu I, Ncebiyik $H$, Karakaş H, Erel O, Sabuncu T. The evaluation of thiol/disulphide homeostasis in diabetic nephropathy. Diabetes Res Clin Pract. 2019;148:249-53.

7. Zhang J, Healy HJ Venuthurupalli S K, Tan KS, Wang Z, Cameron A et al. Blood pressure management in hypertensive people with non-dialysis chronic kidney disease in Queensland, Australia. BMC Nephrol. 2019;20(1:348.

8. Levey AS, De Jong PE, Coresh J, Nahas $\mathrm{ME}$, Astor BC, Matsushita $\mathrm{K}$ et al. The definition, classification, and prognosis of chronic kidney disease: a KDIGO Controversies Conference report. Kidney Int. 2011;80(1):17-28.

9. Levey AS, Inker LA, Coresh J. GFR Estimation: From Physiology to Public Health. Am J Kidney Dis. 2014 May; 63(5): 820-834.

10. Totoli C, Carvalho AB, Ammirati AL, Draibe SA, Canziani MEF. Associated factors related to chronic kidney disease progression in elderly patients. PLoS One. 2019;14(7):e219956

11. Martinez MG, Santos Silva VD, Do Valle AP, De Oliveira RC, Banin VB, Hokama NK et al. Association between sodium intake and urinary fractional albumin and immunoglobulin $\mathrm{G}$ excretion in chronic nondialytic renal disease: a prospective longitudinal study. Nephron. 2019;143(1):62-7.

12. C Hu, L Sun, L Xiao, Y Han, X Fu, X Xiong, et al. Insights into the mechanisms involved in the expression and regulation of extracellular matrix proteins in diabetic nephropathy Curr. Med. Chem., 22 (2015), pp. $2858-2870$

13. Park JS, Kim S, Jo CH, Kim GH. Effects of dietary salt restriction on renal progression and interstitial fibrosis in adriamycin nephrosis. Kidney Blood Press Res. 2014;39(1):86-96.

14. Zou J, Yu Y, Wu P, Lin FJ, Yao Y, Xie Y et al. Serum phosphorus is related to left ventricular remodeling independent of renal function in hospitalized patients with chronic kidney disease. Int $\mathbf{J}$ Cardiol 2016;221:134-140. 